\title{
Alfred Jarry, CEuvres complètes t. IV
}

\section{Ida Merello}

\section{(2) OpenEdition}

\section{Journals}

\section{Edizione digitale}

URL: http://journals.openedition.org/studifrancesi/10029

DOI: 10.4000/studifrancesi. 10029

ISSN: 2421-5856

\section{Editore}

Rosenberg \& Sellier

\section{Edizione cartacea}

Data di pubblicazione: 1 août 2017

Paginazione: 389-390

ISSN: 0039-2944

\section{Notizia bibliografica digitale}

Ida Merello, «Alfred Jarry, Euvres complètes t. IV», Studi Francesi [Online], 182 (LXI | II) | 2017, online dal 01 août 2017, consultato il 10 janvier 2021. URL: http://journals.openedition.org/studifrancesi/10029 ; DOI: https://doi.org/10.4000/studifrancesi.10029

Questo documento è stato generato automaticamente il 10 janvier 2021.

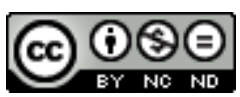

Studi Francesi è distribuita con Licenza Creative Commons Attribuzione - Non commerciale - Non opere derivate 4.0 Internazionale. 


\title{
Alfred Jarry, Euvres complètes t. IV
}

\author{
Ida Merello
}

\section{NOTIZIA}

ALFRED JARRY, Euvres complètes t. IV, sous la direction d'Henri Béhar, édition d'Henri Béhar, Paul Edwards, Matthieu Gosztola et Jean-Paul Morel, Paris, Classiques Garnier 2016, 914 pp.

1 L'edizione di Ubu enchaîné si deve a Henri BÉHAR (pp. 11-184), che ripropone l'edizione Natanson del 1899, ossia preceduta da Ubu Roi. Ubu enchaîné non aveva fatto parlare di sé e i fratelli Natanson avevano preferito accostarlo al primo Ubu. Béhar sfata alcuni luoghi comuni: il carattere più adulto del testo, la cui origine si colloca nuovamente negli anni del liceo, il rovesciamento dei valori, nel momento in cui Ubu passa dal delirio di onnipotenza regale al fastidio per la regalità. In realtà Béhar mostra con finezza come l'Ubu enchaîné rappresenti il doppio di Ubu roi, in quanto Ubu diventa capo degli uomini liberi, quindi sempre capo, e sempre per soddisfare il suo ventre, passando semplicemente da una monarchia a una dittatura. Anche gli altri personaggi conservano lo stesso ruolo avuto nell'Ubu roi. Le osservazioni di Béhar inchiodano il testo anche alla sua omologia con le strutture drammatiche contemporanee, malgrado l'uso di espressioni gergali giovanili o del lessico rabelaisiano. Il curatore ricorda come la prima rappresentazione sia stata postuma di parecchi anni: fu infatti solo nel 1937 che la pièce fu messa in scena dalla compagnia del Diable écarlate di Sylvain Itkine, e usata come un'arma contro il teatro contemporaneo, per far risaltare i valori surrealisti e del trotskismo. Per una versione filologica si è dovuta attendere la messa in scena per la televisione del 1971 di Jean-Christophe Averty. Il testo è presentato con un fitto apparato di note storiche e di filologia testuale.

2 Jean-Paul MOREL cura invece l'edizione di La Chandelle verte (pp. 185-676), basandosi sull'edizione di Maurice Saillet per il «Livre de poche», ma mettendo i testi in ordine cronologico e optando per qualche riclassificazione. Volendo rispettare la distinzione tra testi critici e speculativi, stabilisce infatti di definire pre-speculazioni alcuni comptes 
rendus. La parte più consistente delle cronache è quella che Jarry pubblica sulla «Revue blanche» a partire dal 1896, e delle Spéculations (gennaio 1902) e poi Gestes (estate 1902). Lo stato di salute di Natanson aveva poi convinto Jarry a passare alla «Renaissance latine», dove aveva pubblicato Le Journal d'Alfred Jarry e due nuove gesta, ma non la terza, a seguito di una brouille. È per questo che lo scrittore può passare alla «Plume» (Périple de la littérature et de l'art) e al «Canard sauvage» di Franc-Nohain, dove fa uscire trenta pezzi su trentun numeri. La produzione si conclude con qualche pezzo sul «Figaro», attraverso la mediazione di Fénéon, e su «Poesia» di Marinetti, che ha appena fatto uscire Le Roi Bombance. Morel discute all'inizio sulle ragioni del titolo La chandelle verte, che Jarry ha scelto per le sue Spéculations, rintracciandone la scelta nell'abitudine delle imprecazioni «De par ma chandelle verte», e nei tre significati: suono/colore del "la" nell'organo filosofico inventato da Brian Higgins (1877), moccio del naso, e pene baldanzosamente eretto. Forse, dato l'interesse di Jarry per l'occulto, non si potrebbe escludere anche il valore esoterico delle candele verdi, usate nei sabba e nelle messe nere della fine secolo.

3 L'edizione dei Textes critiques et divers è condotta da Matthieu gosztola, con la partecipazione di Jean-Paul MOREL. Un'edizione completa era già uscita per mano di Henri Bordillon e Bernard le Doze, ma con minore apparato critico; qui viene aggiunta, sottraendola alla corrispondenza, la lettera di Jarry su Messaline di Nonce Casanova. Si tratta per la maggior parte di critica teatrale. Nell'introduzione ne sono riepilogate le caratteristiche: recensioni senza aver visto gli spettacoli, ma fantasticandovi sopra, grande concisione (Jarry veniva pagato a pagina, ma non rinuncia alla sintesi anche quando avrebbe potuto richiedere più spazio), gusto dell'ellissi (Vallette gli rimproverava l'uso di accostamenti chiari forse in un discorso orale, ma non in uno scritto), oscurità ricercata, citazioni da testi che non erano quelli dell'oggetto del discorso. Viene messa in evidenza la grande apertura di Fénéon, che continua a dare spazio sulla «Revue Blanche» ai comptes rendus di Jarry, anche se all'interno della redazione qualcuno aveva avanzato dubbi sulla loro pertinenza. I testi sono accompagnati da fittissimi rimandi in nota e da un'appendice con le varianti. 